\section{As memórias \\ em disputa \\ sobre a ditadura \\ civil-militar na \\ UFRJ: lugares de \\ memória, sujeitos \\ e comemorações}

\section{Andréa Cristina de Barros Queiroz [*]}

\author{
[*] Historiadora da Universidade Federal do \\ Rio de Janeiro (UFRJ) e diretora da Divisão de \\ Memória Institucional/Sistema de Bibliotecas e \\ Informação (SiBI/UFRJ). Rio de Janeiro (RJ), Brasil. \\ andreaqueiroz@sibi.ufrj.br
}

ORCID: HTTPS://ORCID.ORG/0000-0002-7173-375X
Resumo: Este artigo analisa as disputas de memória presentes nas comemorações e nos lugares de memória da Universidade Federal do Rio de Janeiro (UFRJ) durante o período da ditadura civil-militar e como a própria universidade lida com essas memórias. A história centenária da UFRJ tem como traço marcante, desde a sua origem em 7 de setembro de 1920, a fragmentação de suas unidades e, por conseguinte, de seus acervos, que se encontram dispersos em seus diversos campi. As marcas dessas memórias em disputa sobre o passado e sobre a vida universitária durante a ditadura estão presentes no cotidiano da comunidade acadêmica e da sociedade, sobretudo, porque muitos dos sujeitos que estavam na gestão da instituição também exerceram cargos de destaque na administração federal.

Palavras-chave: Memória Institucional; Ditadura; Universidade Federal do Rio de Janeiro (UFRJ).

\section{The disputed memories about the civil- military dictatorship at UFRJ: places of memory, subjects and celebrations}

\begin{abstract}
This article analyzes the memory disputes present in the celebrations and in the places of memory of the Universidade Federal do Rio de Janeiro (UFRJ) during the period of the civil-military dictatorship and how the University itself deals with these memories. The centenary history of UFRJ has a striking feature, since its origin on September 7 , 1920, the fragmentation of its units and, consequently, of its collections, which are dispersed on its various campuses. The marks of these disputed memories about the past and about university life during the dictatorship are present in the daily life of the academic community and society, especially because many of the subjects who were in the management of the institution also held prominent positions in the federal administration.
\end{abstract}

Keywords: Institutional Memory; Dictatorship; Universidade Federal do Rio de Janeiro (UFRJ). 
A

origem da primeira universidade pública do país, que comemorou em 2020 o seu centenário, tem relação com a influência positivista na política educacional brasileira após a Proclamação da República (Cunha, 2007, p. 132) e com a reunião, por interesses do governo federal, de três cursos superiores: medicina; engenharia e direito, criados ainda no século XIX para atender uma demanda de formação profissional e social com a transmigração da Corte portuguesa para o Brasil em 1808.

Portanto, a criação da Universidade do Rio de Janeiro (URJ), pelo Decreto n. 14.343, de 7 de setembro de 1920, durante o governo de Epitácio Pessoa (1912-1922), interagiu com a intenção de centralidade do poder federal para a reunião desses cursos profissionais preexistentes na universidade, que remontava à Reforma Carlos Maximiliano, ${ }^{1}$ de 1915, que definia em seu 6oartigo que "o Governo Federal, quando achar oportuno, reunirá em Universidade as Escolas Politécnica e de Medicina do Rio de Janeiro, incorporando a elas uma das Faculdades Livres de Direito" (Fávero, 2010, p. 26). Na prática, o que foi modificado dessa proposição inicial foi que houve a união das duas faculdades livres de direito na Faculdade Nacional de Direito, que reunida à Escola Politécnica e à Faculdade Nacional de Medicina se tornaram a URJ.

É importante destacar que não existia um sentimento de identidade, nem de unidade na URJ, ou seja, ela era fragmentada. As suas escolas não possuíam relações orgânicas e estavam espacialmente dispersas. Além disso, não havia produção de pesquisa, a instituição estava voltada apenas para o ensino, nos permitindo fazer uma primeira reflexão sobre o caráter de universidade propriamente dito. Essa fragmentação, se opondo à ideia de universidade stricto sensu perdurou como um grande paradigma ao longo da trajetória da instituição.

Com a promulgação da Lei n. 452, de 5 de julho de 1937, a Universidade do Rio de Janeiro foi reorganizada e transformada em Universidade do Brasil (UB). De imediato, houve um grande investimento do governo federal para o crescimento de seus cursos e de seu corpo social com a incorporação de diversas instituições já existentes, como também a constituição de novos lugares de memória e acervos, embora permanecesse fragmentada, já que continuava inexistindo uma relação orgânica entre essas unidades. Ressaltamos que o crescimento da instituição estava ligado ao contexto sociopolítico do início da ditadura do Estado Novo de Getúlio Vargas (1937-1945), pautada numa política para universidade: autoritária, centralizadora, desenvolvimentista e sem autonomia. Segundo Fávero (2010, p.

' A Reforma Carlos Maximiliano foi realizada pelo Decreto n. 11.530, em 18 de março de 1915, alterando a Reforma Rivadávia Correa, criada pelo Decreto n. 8.659, em 5 de novembro de 1911, ao instituir a necessidade da organização de uma universidade pelo poder federal (Fávero, 2010, p. 30). 
53), "aos professores e aos alunos da UB, eram proibidas quaisquer atitudes de caráter político-partidário ou comparecer às atividades universitárias com uniforme ou emblema de partidos políticos". No que se refere ao desenvolvimentismo, a Universidade do Brasil representaria a vitrine de um projeto de educação pensado pelo Estado autoritário e divulgado para o restante do país como modelo a ser seguido por todas as universidades, inclusive as que ainda seriam criadas.

A Universidade do Brasil passou a designar-se Universidade Federal do Rio de Janeiro (UFRJ) somente em 20 de agosto de 1965, com a Lei n. 4.759, durante a ditadura civil-militar (1964-1985), marcando não apenas a ideia de padronização de todas as universidades do país no contexto autoritário, mas também reforçando o paradigma centralizador e elitista da universidade, conjugado ao ideal moderno-conservador e autoritário do regime, que pôde ser observado inclusive na gestão de seus reitores. Lembramos que apenas os três cursos fundadores da URJ se revezaram na gestão da reitoria da instituição. Identificamos que todos os reitores, de 1920 a 1985, foram oriundos da Faculdade de Medicina, da Faculdade de Direito ou da Escola Politécnica, dinâmica apenas rompida com a eleição do reitor Horário Cintra de Magalhães de Macedo, em 1985, que era químico.²

\section{A universidade e a ditadura}

Ao analisar o contexto autoritário no cotidiano das universidades brasileiras, durante a ditadura civil-militar, Motta (2014, p. 75$)$ salientou que as reformas educacionais foram resultados das tensões e negociações entre diferentes setores que apoiavam o governo e as pressões dos movimentos estudantis que, a partir de 1965, realizaram protestos e manifestações públicas contra a política universitária do regime militar.

As reformas implantadas na ditadura se caracterizaram por uma modernização conservadora e autoritária, que na prática significou: a valorização do ideal de eficiência e racionalidade de recursos; o aumento do número de vagas; a reorganização da carreira docente; a criação dos departamentos e o fim das cátedras; o incentivo à pós-graduação e à pesquisa; como também: a censura às ideias de esquerda; a repressão e o afastamento dos meios acadêmicos dos defensores dos ideais comunistas; o cerceamento do movimento estudantil; a criação de Agências Especiais de Informação para controlar o corpo social da universidade; a censura à pesquisa (reforçamos que houve incentivo à pesquisa, mas havia um controle sobre o que se pesquisava), à publicação e à circulação de livros, sobretudo aqueles ligados

${ }^{2}$ Ver a galeria de reitores da UFRJ disponível em: http://memoria.sibi.ufrj.br/index.php/reitores-da-ufrj. Acesso em: 17 ago. 2020. 
aos temas da esquerda; e a criação e a valorização de disciplinas que atrelavam educação ao civismo (Motta, 2014, p. 15).

Um dos grandes defensores e idealizadores da reforma universitária de 1968 foi o reitor da UFRJ Raymundo Moniz de Aragão (1966-1969), que também foi ministro da Educação e Cultura interino, de 30 de junho a 4 de outubro de 1966. Enquanto esteve à frente do ministério, Moniz de Aragão promoveu as primeiras leis relativas à reforma universitária. Além disso, também contribuiu para a criação do Conselho Federal de Cultura (CFC), órgão responsável por fomentar as políticas culturais e ideológicas do governo por meio da valorização da pátria, promovendo cursos e projetos de civismo atrelados à cultura e à educação; da censura às produções culturais que criticavam a ditadura; e da perseguição daqueles que eram contrários ao regime autoritário. Além de Moniz de Aragão, outros reitores da UFRJ também participaram do CFC, como os professores Pedro Calmon M. de Bittencourt (19511966); Djacir Lima Menezes (1969-1973) e Deolindo Augusto de Nunes Couto (1950-1951). Segundo Tatyana Maia (2014, p. 52), a participação ativa de intelectuais no interior do Ministério da Educação e Cultura (MEC) expôs uma das faces do regime de exceção que se instalou no país com o golpe de 1964; liderada pelos militares, a ditadura contou com a colaboração de civis no controle, vigília e denúncia como estratégias de manutenção.

Uma das formas de propagar os ideais da cultura política autoritária do regime era assegurar, por meio da educação, os conteúdos de civismo a serem disseminados na universidade, especialmente com a disciplina de Estudos de Problemas Brasileiros (EPB). Como destacou Maia (2014, p. 55), entre 1971 e 1980, por meio do Fórum de Ciência e Cultura da UFRJ, foi organizado o "Curso de atualização sobre problemas brasileiros" destinados à capacitação de docentes de ensino superior para ministrar a disciplina de EPB. O curso foi proposto pelo ex-reitor Pedro Calmon como solução provisória à inexistência de um curso superior de Estudos Brasileiros. Ele foi organizado em conferências temáticas que foram editadas pela UFRJ, a partir de 1972, na publicação Cadernos de Estudos Brasileiros, coordenada por Moniz de Aragão. Entre os principais conferencistas do curso estavam os três reitores da universidade que também eram conselheiros no CFC: Moniz de Aragão, Djacir Menezes e Pedro Calmon. ${ }^{3}$

Com base nessas evidências, podemos perceber que personagens importantes da comunidade acadêmica da universidade participaram, negociaram e colaboraram com o regime autoritário. Se houve oposição e resistência, de um lado, sobretudo, com o movimento estudantil e com os movimentos sociais liderados por servidores (técnicos e docentes) para

${ }^{3}$ O acervo referente à documentação dessas conferências e cursos encontra-se em um dos lugares de memória da universidade, a antiga Biblioteca Central, atual Biblioteca Pedro Calmon do Fórum de Ciência e Cultura, integrada ao Sistema de Bibliotecas e Informação da UFRJ, no campus da Praia Vermelha. 
o retorno dos exilados à universidade no pós-1979 com a Anistia, também houve colaboração e negociação com a ditadura, do outro, especialmente por parte dos dirigentes da instituição e da parcela conservadora dos docentes e técnicos que apoiavam o regime autoritário. Assim, nos deparamos com uma das seletividades da memória dentro da universidade, pois durante muito tempo houve um esquecimento que parte da comunidade acadêmica colaborou com o regime, e no bojo da Anistia, no pós-1979 e com a redemocratização se consagrou uma narrativa de reconciliação com o passado, como se na universidade, grosso modo, todos tivessem se empenhado na luta pela redemocratização. Como destacou Daniel Aarão Reis Filho (2000, p. 71), durante o processo de redemocratização elaborou-se uma memória de resistência que apresentava os civis como defensores incontestes da democracia, silenciando as relações de apoio, participação e legitimação ao regime de vários setores da sociedade civil durante os 21 anos de existência da ditadura.

Colaboração e apoio por vezes declarados publicamente, a exemplo do professor Eremildo Luiz Vianna catedrático de História Antiga e Medieval e ex-diretor da Faculdade Nacional de Filosofia (FNFi), de 1957 a 1963, e do Instituto de Filosofia e Ciências Sociais (IFCS $)^{4}$ durante quase todo o período da ditadura. Ele se tornou o personagem mais famoso da universidade pela sua atuação no que se refere à perseguição e à expulsão dos professores e estudantes da FNFi e posteriormente do IFCS. Pouco tempo depois do golpe, em 16 de maio de 1964, Eremildo Vianna enviou um relatório intitulado "Professores comunistas da Faculdade Nacional de Filosofia" para o então general Arcy da Rocha Nóbrega, que presidia a Comissão de Investigação da Universidade do Brasil (Ciub). Além de denunciar diversos colegas do Departamento de História, Eremildo Vianna denunciou 44 professores da UB acusados de subversão e afirmava que todos eles formavam uma célula comunista na universidade de nome Anchieta, como analisou Ludmila Pereira (2010, p. 99).5

Por sua relação com a ditadura e o papel desempenhado como delator de seus colegas de trabalho, tanto na universidade quanto na Rádio MEC (onde foi presidente, cargo que conseguiu ocupar após perseguir e expulsar a então presidente da rádio, a professora Maria Yedda Linhares, sua colega no Departamento de História), Eremildo Vianna foi alvo de muitas críticas em crônicas da grande imprensa, como na coluna do Stanislaw Ponte Preta (Sérgio Porto) no jornal Última Hora; nas crônicas do jornalista Elio Gaspari (2002, p. 225), que o descrevia como um "Querubim do regime militar". Gaspari foi aluno do curso de História na FNFi e foi expulso por Eremildo no início dos anos 1960; por fim, nas reportagens do Jornal do Brasil, que publicou na sessão Informe JB do ano de 1978 uma sequência de

\footnotetext{
${ }^{4}$ Em 1965, o curso de História passou a integrar o IFCS e em 1968 a FNFi foi desmembrada e dissolvida.

5 Em 1969, durante o governo do general presidente Artur da Costa e Silva (1967-1969), 45 professores da UFRJ foram efetivamente cassados, aposentados compulsoriamente; a maioria constava da "Lista de Eremildo".
} 
matérias sobre as atividades de Eremildo Vianna na ditadura, contendo entrevistas com professores cassados da UFRJ (Eremildo..., 6 abr. 1978). O jornal também publicou que a Ciub descobriu fraudes no período em que Eremildo esteve à frente da FNFi, o indiciando por falsificar documentos (Pereira, 2010, p. 101).

No pós-golpe de 1964, essas ações de investigação e perseguição em várias universidades pelo país ficaram conhecidas como "Operação Limpeza" e tinham como principal objetivo afastar da esfera pública comunistas, socialistas, trabalhistas e nacionalistas de esquerda (Motta, 2014, p. 25). Um exemplo dessa perseguição ao corpo social da então Universidade do Brasil foi a prisão, em abril de 1964, imediatamente após o golpe, do físico e professor da FNFi Plínio Süssekind Rocha e do médico e professor da Escola de Enfermagem Manoel Isnard de Souza Teixeira; em seguida, em agosto do mesmo ano, foi preso o físico e professor da FNFi José Leite Lopes.

Ressaltamos que a principal legislação autoritária, criada pelo general presidente Artur da Costa e Silva (1967-1969) como mecanismo de coerção da vida universitária foi o Decreto-lei n. 477, de fevereiro de 1969, notadamente conhecido como "AI-5 das universidades". ${ }^{6}$ Professores, estudantes e técnico-administrativos acusados de subversão ao regime eram punidos com a expulsão da universidade sem o direito de retorno a qualquer outro estabelecimento de ensino por um determinado período. Na prática, visava inibir a produção intelectual de uma geração de acadêmicos considerados pela ditadura como comunistas. Mas a colaboração dos gestores da UFRJ com a ditadura pode ser identificada também nos mecanismos reguladores e disciplinares universitários, como o Código Disciplinar n. 135, analisado por Freitas (2014) e criado pela instituição antes da aprovação do Decreto-lei n. 477, que também visava regulamentar a aplicação de sanções disciplinares à comunidade acadêmica.

Para completar a estruturação desse aparato autoritário e coercitivo dentro das universidades, em 1971, foram criadas as Assessorias Especiais de Segurança e Informação (Aesis), que tinham a função de patrulhamento e vigília e, sobretudo, levantar informações dentro de cada instituição de ensino superior para "monitorar elementos considerados subversivos" (Müller e Fagundes, 2014, p. 46).

Todos esses mecanismos de cerceamento foram eficazes para eliminar da universidade todos aqueles que eram contrários à ditadura e estavam sendo vigiados pelos setores conservadores da instituição antes mesmo do golpe. Com isso, foi provocado um grande esva-

${ }^{6}$ Lembramos que o Ato Institucional n. 5, o Al-5, foi decretado em 13 de dezembro de 1968, e promoveu um acirramento do regime de autoritário, cassando direitos civis e políticos, fechando o Congresso, entre outras medidas coercitivas. Foi com base nesse ato que muitos professores da UFRJ foram expulsos da universidade, sendo aposentados de forma compulsória. 
ziamento científico, intelectual, político, cultural e social da universidade, com a interrupção de muitas pesquisas e de diferentes projetos.

\section{Lugares de memória, sujeitos e comemorações}

A memória é uma construção do tempo presente que compartilha vivências e experiências socioculturais e políticas de um passado individual ou coletivo e, por isso, está sujeita às questões de subjetividade e seletividade. A relação entre lembrança e esquecimento que compõe a memória pode ser alterada de acordo com a conjuntura política, social, cultural e econômica de uma época, como ressaltou Huyssen (2000). Na dinâmica do que é lembrado e do que é esquecido se inserem também as comemorações, importante mecanismo do presente para ressaltar a identidade e a memória de indivíduos, grupos sociais e instituições. Para Paul Ricouer (1996) a comemoração é um trabalho de construção de uma memória coletiva que difere da rememoração que parte de um processo de elaboração individual, mas ambas ganham significados a partir do presente. Dialogando com essa ideia, Catroga (2001) ressaltou que toda comemoração pressupõe decisões acerca do que lembrar e do que esquecer, e tais decisões são tomadas por indivíduos ou por grupos sociais no tempo presente em que a comemoração é realizada. Para o autor, as comemorações envolvem decisões políticas, mais ou menos carregadas pelo desejo correlato de fazer esquecer - silenciar e apagar - ou fazer lembrar de acontecimentos, pessoas e projetos.

As sociedades necessitam preservar as suas memórias para compreenderem a si mesmas, ressaltou Pierre Nora (1993, p. 13), e para isso possuem uma "vontade de memória", um desejo do presente em preservar o passado, e esse desejo que possibilita a existência de lugares de memória. Enfim, as memórias, individual e coletiva, sempre se fazem em algum lugar que lhes imprime uma referência. Dessa forma, o lugar de memória seria toda unidade significativa, de ordem material ou ideal, que a vontade dos homens ou o trabalho do tempo converteu em elemento simbólico do patrimônio memorial de uma comunidade qualquer. De acordo com Santiago Júnior (2015), a abertura para a cultura do patrimônio demonstra que o lugar de memória, em vez de um ritual de uma sociedade com memória fraturada, é um exercício múltiplo de formação dos passados das diversas comunidades políticas.

Para contribuir nesse debate tomaremos como primeira análise as memórias em disputa em torno da Cidade Universitária da UFRJ, na ilha do Fundão, um lugar de memória institucional relacionado ao patrimônio modernista da universidade e do país, que tem a sua construção e inauguração comemorada e rememorada em temporalidades e conjunturas distintas, por dois sujeitos políticos (Getúlio Vargas e Médici) que disputaram o legado sobre esse espaço e sobre a memória institucional oficial. 
A Cidade Universitária tem a sua origem ligada ao ideal de universidade grande e exemplar para a nação, respaldada pelo projeto político-educacional, do governo de Getúlio Vargas durante a ditadura do Estado Novo. Contudo, foi apenas inaugurada em $1^{\circ}$ de outubro de 1953, em seu segundo governo, com o prédio do Instituto de Puericultura e Pediatria Martagão Gesteira (IPPMG), uma obra modernista, com a assinatura premiada do paisagista Roberto Burle Marx e do arquiteto Jorge Machado Moreira, que também projetou o prédio da Faculdade de Arquitetura e Urbanismo (FAU), em 1957, que foi concluído em 1961; os dois projetos foram premiados na Bienal de Arquitetura de São Paulo.

Houve uma série de interrupções nas obras de construção dos demais prédios da Cidade Universitária, em razão das inúmeras crises econômicas que se agravaram com o suicídio de Getúlio Vargas, em 1954, e com as tensões políticas promovidas com a mudança da capital do Rio de Janeiro para Brasília, em 1960. Dessa forma, é importante destacar que somente no período da ditadura civil-militar que as obras para a construção dos novos prédios foram retomadas na ilha do Fundão, mas com bastante diferença em relação ao projeto original de Vargas.

Foi nesse contexto que o general presidente Emílio Garrastazu Médici (1969-1974), durante as comemorações dos 150 anos da Independência do Brasil, em 7 de setembro de 1972, realizou a solenidade para a nova inauguração da Cidade Universitária. Destacamos que a data escolhida para a (re)inauguração também coincide com a efeméride de comemoração da própria universidade. Segundo Helenice Silva (2002, p. 432), "as comemorações buscam, nessa rememoração de acontecimentos passados, significações diversas para uso do presente".

Sobre essa entrega simbólica à sociedade e enaltecendo o contexto de comemoração do Sesquicentenário da Independência com o aniversário da UFRJ, em seu discurso, o presidente Médici exaltou a perspectiva de um legado histórico de sua gestão e a importância de seu governo entregar a Cidade Universitária não somente para a comunidade acadêmica da UFRJ, mas também para o país naquele momento:

Estava ainda no começo o atual período governamental, quando determinei se retomassem imediatamente as obras da Cidade Universitária, na Ilha do Fundão, para que esse projeto, na sua primeira etapa, se ultimasse até o Sesquicentenário da Independência. Providenciados, ato contínuo, os recursos financeiros, instituídos os órgãos de coordenação dos trabalhos, estes se desenvolveram segundo os cronogramas estabelecidos, sob a supervisão vigilante, quer das autoridades universitárias, quer do Ministro da Educação e Cultura, quer da própria Presidência da República. Graças não só a isso, mas também a exemplar dedicação e competência dos responsáveis diretos por esse empreendimento, no qual se investiram, até agora, cerca de Cr\$ 400 milhões, procedo à entrega, solene, neste momento, da Cidade Universitária do Rio de Janeiro à sua ilustre e proficiente corporação de professores e alunos. Dentro da Semana da 
Independência, data para isso estipulada há mais de dois anos e meio, transforma-se, desta maneira, pela eficácia da ação administrativa, em promissora realidade, transcendente deliberação que se insere, de modo eminente, no quadro das providências articuladas para democratizar o ensino e assegurar a todos, nos termos constitucionais, o direito à educação (UFRJ, 7 set. 1972a).

Em agradecimento à retomada das obras da Cidade Universitária e de sua (re)inauguração pelo general presidente, o então reitor Djacir Menezes (1969-1973) destacou o seu apoio e o da universidade ao governo militar:

Não podia a Universidade calar, nesta hora e nesta Semana Cívica, sua gratidão ao Presidente que, no limiar de seu governo, decidiu, entre as grandes tarefas que se atulhavam, a realização do campus que agora se inaugura. E a decisão memorável na história da educação superior do país revela inspiração da mais íntima sintonia com a significação do ano remoto que marcou o madrugar de uma pátria. [...] Senhor Presidente, conheço sua austeridade e sua nobre e superior indiferença aos festejos da lisonja que envolve sempre o exercício do poder. Nossas palavras não dissentem dessa linha moral que lhe define o caráter de soldado e dignidade de cidadão. E é traduzindo o sentimento do nosso mais alto Colegiado, que é o Conselho Universitário, que agradeço àquele que deu o impulso às obras paralisadas e abriu perspectivas de estudo e trabalho a professores e alunos, nessa atmosfera onde se configura o ideal científico e ético da nacionalidade. Exprimo aqui a gratidão e a lealdade para com um Presidente que, em meio às sugestões contrárias teve a visão nítida do grande objetivo. É um ato insopitável de justiça a palavra comovida de reconhecimento que lhe transmite o Reitor em nome da Comunidade que tem a honra de representar, ampliando o agradecimento àqueles que mais de perto assistem a V. Ex. ․ nos encargos do Governo, com especial menção do Senhor Ministro da Educação. Brindo na presença de V. Ex. å a continuidade da renovação institucional do país, a reorganização das universidades e a segurança reconquistada da família brasileira (UFRJ, 7 set. 1972b).

No que diz respeito a esse discurso em agradecimento, de exaltação, de celebração e de apoio do reitor Djacir Menezes ao presidente Médici, ele demonstra o que já foi analisado, sobre as relações estabelecidas entre o governo e os gestores da universidade, sobretudo, a ideia da conjugação de um projeto de educação pública atrelado ao ideal cívico e aos discursos moralizantes do governo ditatorial.

Ressaltamos que, se de um lado houve investimentos do governo federal para modernização da UFRJ, incrementando e retomando obras e incentivando pesquisas, sobretudo no campo da tecnologia e da saúde; por outro, houve um enorme retrocesso, marcado pelo autoritarismo com a interrupção de muitos projetos, especialmente, na área das humanidades, letras e artes; e a perseguição e a expulsão do corpo social contrário à ditadura. Desta- 
camos que, no ano de 1972, o Conselho Universitário da UFRJ concedeu ao presidente Médici o título de Doutor Honoris Causa em reconhecimento ao investimento empregado por ele na modernização da universidade.

A concessão desse título nos mostra não apenas as relações estabelecidas entre a gestão da UFRJ e a ditadura, mas também os impactos dessa comemoração para a memória da instituição. A apropriação da data 7 de setembro para celebrar a (re)inauguração da Cidade Universitária, na verdade interage com uma tripla comemoração - a da criação da UFRJ; a dos 150 anos da Independência do Brasil e a da Cidade Universitária (que na verdade foi inaugurada em $1^{o}$ de outubro de 1953 como demonstramos). Precisamos entender os sentidos do ato de se comemorar tais efemérides e como elas estabeleceram um diálogo com aquele presente histórico e com as intenções do governo em celebrar um novo momento para o país e para a universidade, a ideia de que se teria chegado ao "país do futuro", com grandes modernizações projetadas e realizadas no presente. Ideia que pode ser identificada tanto no discurso de Médici quanto no do reitor da UFRJ. De acordo com Janaína Cordeiro (2015, p. 310), "as comemorações do sesquicentenário deveriam ser - e foram -, desde o início, uma grande comemoração dos novos tempos que o governo acreditava estar construindo. Mesmo quando se voltava aos remotos tempos da Independência, o que importava nesse retorno ao passado era festejar essa mudança de status; de eterno país do futuro, transformara-se, finalmente, no país do presente".

Ainda podemos fazer outra reflexão sobre os impactos dessas comemorações na construção da memória institucional, a de um enquadramento da memória (Pollak, 1989) da sociedade e de parte da comunidade acadêmica da UFRJ de que a Cidade Universitária na ilha do Fundão teria sido um projeto arquitetônico e urbanístico projetado pela ditadura civil-militar, sobretudo, para afastar os estudantes da região do Centro do Rio de Janeiro, palco de muitas manifestações sociais e políticas contrárias à ditadura. Nessa região também se concentravam algumas unidades da UFRJ, como: a Faculdade Nacional de Direito; a Escola Politécnica (atual prédio do Instituto de Filosofia e Ciências Sociais e Instituto de História); a Escola Nacional de Música; entre outras unidades. Dessas citadas, apenas a Escola Politécnica foi transferida para a Cidade Universitária para ocupar o prédio do Centro de Tecnologia (CT). As demais unidades permaneceram em suas sedes no Centro do Rio de Janeiro, contrariando essa memória seletiva sobre o afastamento dos estudantes da parte central da cidade para concentrá-los numa ilha.

Inaugurada, simbolicamente, através de seu Instituto de Pediatria, em $1^{\circ}$ de outubro de 1953, nossa cidade universitária não chegou a materializar os sonhos dos que a projetaram: não recebeu todos os institutos e escolas da universidade [...]. Sobre sua construção, impera a visão de ter sido idealizada pelo regime militar, esvaziada propositalmente, em área distante do centro da cidade, com grandes distâncias entre um centro 
e outro, de forma a isolar e enfraquecer o movimento estudantil. O desconhecimento da história - ou a falta dela, ocasionada pela inexistência de produções - bem como o privilegiar de aspectos seletivos da memória, muitas vezes fazem com que lugares importantes do processo histórico e das existências passadas sejam indevidamente percebidos. Reduzir a história da construção de nosso campus ao período da Ditadura Militar nos levaria a desconsiderar aspectos fundamentais para o entendimento da consolidação da instituição universitária no Brasil (Oliveira, 2013, p. 14-15).

Sabemos que a memória é seletiva e pode sofrer alterações quando ela é articulada ou expressa, como analisou Pollak (1992, p. 204). Enfim, o projeto urbanístico e arquitetônico modernista da cidade universitária começou a ser planejado durante a ditadura varguista, com pretensões de valorização de um Brasil moderno a servir de modelo para as demais universidades que seriam criadas pelo país. O ministro da Educação e Saúde de Vargas, Gustavo Capanema, criou uma comissão com arquitetos e engenheiros da universidade e com outros convidados para a elaboração desse projeto. Contudo, antes mesmo de se construir seus futuros prédios, primeiro foi preciso definir a escolha do melhor local onde seria erguida a Cidade Universitária da então Universidade do Brasil. Considerando-se, com isso, fatores de ordem política e social, econômica e técnica. Foi somente no final do Estado Novo, em 1945, que os membros da comissão e o governo chegaram à conclusão de que inexistia um local totalmente apropriado para a obra. Após mais de uma década de discussões e de diferentes locais propostos, ${ }^{7}$ definiram que antes de se construir os prédios da Cidade Universitária, deveria ela mesma ser construída. Dessa forma, o arquipélago de nove ilhas ${ }^{8}$ que ficava próximo a Manguinhos, à Avenida Brasil e à ponte de acesso à ilha do Governador foi aterrado para que houvesse espaço físico apropriado para abrigar a futura Cidade Universitária (Oliveira, 2013, p. 15-16).

Portanto, podemos perceber que a cidade universitária compõe o patrimônio cultural modernista universitário brasileiro pela sua trajetória e pelo seu projeto urbanístico e arquitetônico. Seja como for, a cidade universitária é um projeto da ditadura varguista que foram retomados durante seu governo democrático, mas seu crescimento e expansão foram retomados durante a ditadura civil-militar (1964-1985), a partir do incremento financeiro e investimentos para a conclusão das obras interrompidas diversas vezes pelos governos

\footnotetext{
7 Foram propostos os seguintes locais: Praia Vermelha, incluindo a enseada de Botafogo; Quinta da Boa Vista, abrangendo áreas que hoje compreendem São Cristóvão, Mangueira e parte do Maracanã; Lagoa Rodrigo de Freitas; Niterói; Vila Valqueire e Manguinhos,

8 As nove ilhas eram: Catalão, Baiacu, Cabras, Fundão, Pindaí do França, Pindaí do Ferreira, Bom Jesus, Sapucaia e Pinheiros.
} 
anteriores. E, por isso mesmo, é um espaço de recordação (Assmann, 2011) que representa essas memórias em disputa.

Outra marca da ditadura e do autoritarismo do governo militar sobre a universidade refere-se à invasão, por forças policiais, da Faculdade Nacional de Medicina (FNM), na Praia Vermelha, em 1966, e à demolição do seu prédio histórico, em 1975. Esses dois eventos e as memórias construídas sobre eles transformaram a ausência desse espaço em um lugar de memória da ditadura na UFRJ.

Essa invasão ficou conhecida, sobretudo pelas manchetes dos jornais, como "massacre da Praia Vermelha", pela quantidade de estudantes feridos dentro de um ambiente de ensino superior federal. O referido massacre ocorreu na madrugada do dia 22 para o dia 23 de setembro de 1966, no histórico prédio da Faculdade Nacional de Medicina da UFRJ. ${ }^{9}$ Lembramos que no dia 13 de setembro de 1966, os estudantes da FNM deflagraram greve em solidariedade aos universitários da Faculdade Nacional de Direito, que protestavam contra o pagamento das anuidades, e cujo Diretório Acadêmico (Caco) fora dissolvido pelo Conselho Universitário da UFRJ.

O episódio do massacre deixou cerca de seiscentos estudantes feridos; apesar de não ter havido mortes, esse confronto gerou um forte impacto na sociedade, especialmente porque a FNM era um dos espaços mais elitizados da universidade desde a sua criação, mesmo que os estudantes atingidos tenham sido de vários cursos da UFRJ. Na véspera do massacre, vários universitários do país saíram às ruas em passeata pelo Dia Nacional de Luta Contra a Ditadura convocada pela União Nacional dos Estudantes (UNE) para protestarem contra a cobrança de anuidades nas universidades públicas, contra o projeto de reforma universitária inspirado pelo governo dos Estados Unidos e contra a ditadura que se institucionalizava no país. A passeata foi duramente reprimida pela polícia militar e os estudantes se refugiaram no prédio da FNM, que foi cercado pelas tropas.

Apesar do aparato policial que isolou a Urca e a Praia Vermelha dos demais pontos da cidade, os estudantes realizam a passeata programada pela Avenida Pasteur, saindo da Faculdade de Economia [campus da Praia Vermelha] para a Faculdade Nacional de Medicina, onde o prédio é ocupado pelos estudantes. No trajeto, os estudantes vaiam a polícia e o Governo, aos brados de "Fora a Polícia" e "Abaixo a Ditadura"(30 anos..., 1996, p. 4).

${ }^{9}$ No governo de Wenceslau Braz (1914-1918), em 4 de maio de 1916, foi lavrado o contrato de construção do edifício que abrigaria a Faculdade Nacional de Medicina, com o projeto do arquiteto Antonio Jannuzzi, que inicialmente previa a construção de três edifícios, incluindo um hospital, mas apenas um foi erguido. A obra foi concluída em 12 de outubro de 1918, e as aulas da faculdade passaram a funcionar a partir de 1919. 
O então reitor Pedro Calmon e uma comissão de pais tentaram negociar com a polícia a saída pacífica dos alunos. Dessa negociação, há uma frase que ainda ecoa na memória da comunidade acadêmica, a de que o reitor teria dito ao comandante da PM que os policiais não poderiam entrar na universidade, a não ser pelo vestibular. Contudo, não havia como negociar com quem tinha a intenção desde o início de reprimir, haja vista a quantidade de militares que estavam diante do portão da FNM. Como a negociação não surtiu efeito, os estudantes decidiram permanecer no local e a polícia invadiu a faculdade na madrugada. Esse foi considerado o primeiro grande confronto entre estudantes e as forças de repressão do governo pós-1964, retomado depois com as grandes passeatas de 1968. Inclusive, no ano de 1968 houve outra invasão à UFRJ, dessa vez no Teatro de Arena Carvalho Neto, localizado no Palácio Universitário, na Praia Vermelha, onde os estudantes estavam reunidos em assembleia, e a repressão policial militar além de espancar, prendeu vários estudantes no campo de futebol do Botafogo, situado próximo ao campus.

Para o reitor Aloísio Teixeira (2007-2011) que era estudante universitário do curso de Economia da UFRJ naquela época e participou do protesto em 1966:

estávamos na faculdade e a polícia cercou o prédio. Combinamos que ninguém sairia enquanto eles não fossem embora, mas de madrugada a polícia invadiu a faculdade e agrediu todo mundo. As pessoas começaram a subir as escadas correndo até o terceiro andar, mas quando chegamos lá em cima não tinha mais para onde ir. A polícia então formou um corredor polonês do terceiro andar até o térreo e tivemos que descer embaixo de cacetada (Brito, 2006).

A derrubada do prédio da FMN pela ditadura tem relação, segundo relatos de ex-alunos e professores, com o episódio do massacre, mas também com a necessidade do governo ditatorial de investir na retomada e expansão da Cidade Universitária, de acordo com a política de modernização conservadora e autoritária já analisada. Para o ex-aluno e professor da FNM, George Doyle Maia (1996, p. 13),

o Conselho Universitário nada mais fez do que cumprir com uma determinação que estabelecia a obrigatoriedade de venda de todos os imóveis da Universidade para o término das obras da Ilha do Fundão. Poderíamos ter lutado pelo tombamento, mas ninguém protestou. Os engenheiros, por exemplo, conseguiram salvar o prédio de Largo São Francisco [atual IFCS]. O mesmo aconteceu com os estudantes da Faculdade 
de Direito, na Moncorvo Filho, e com o Reitor Pedro Calmon, que conseguiu salvar o prédio do Hospital dos Alienados [Palácio Universitário]. ${ }^{10}$

Atualmente, a lembrança do antigo prédio derrubado se relaciona à preservação de uma pedra com uma placa referindo que ali existiu a FNM, mas sem nenhuma reflexão sobre a sua história ou a sua memória. O local hoje é ocupado pelo campus da Praia Vermelha da Universidade Federal do Estado do Rio de Janeiro (Unirio). De acordo com depoimentos de professores concedidos a Maia (1996), uma parcela do corpo docente fez um acordo (formalmente ou não), para que o prédio fosse vendido em troca dos recursos que possibilitariam a conclusão do Hospital Universitário (HU) na Cidade Universitária, que estava com as suas obras paralisadas. Dentre os docentes que participaram da negociação, estava o médico e professor Clementino Fraga Filho, que foi reitor da UFRJ (1966-1967).." Segundo os depoimentos (Maia, 1996), o prédio seria vendido à Eletrobrás, mas a empresa, que possuía dívidas com a União, acabou fechando um acordo com o governo militar; com essa negociação a UFRJ conseguiu verbas para concluir o HU, e a Unirio, cujo reitor era Guilherme Figueiredo, irmão do general João Baptista Figueiredo, o último presidente do regime militar (1979-1985), comprou o terreno. Mas para alguns professores e, sobretudo, para os alunos que participaram da resistência estudantil em 1966 na FNM, a demolição do prédio, em 1975, funcionou, para além dos interesses de especulação financeira, também como um ato de punição e retaliação pela oposição feita pelo movimento estudantil.

A universidade, a partir de sua Comissão da Memória e Verdade, da qual falaremos adiante, planeja demarcar esse espaço, que não mais pertence à instituição, mas que representa simbolicamente um lugar de memória da atuação da ditadura na UFRJ. Com essa demarcação a intenção não seria apenas identificar o local como um lugar de resistência dentro da universidade. A proposta seria marcar a ausência do prédio histórico também como um espaço simbólico de recordação (Assman, 2011), por todos os arbítrios cometidos pelo autoritarismo do regime militar (perseguições, invasões, demolições, censura, expulsões, prisões, tortura e assassinatos), e, dessa forma, não somente fazer lembrar, mas incentivar novas pesquisas a partir dos acervos existentes nos diversos arquivos, museus e bibliotecas da universidade, e com um totem de informações, direcionar o público para esses lugares de memória que guardam, preservam e disseminam o patrimônio memorialístico da UFRJ, contendo inclusive depoimentos com o trabalho de história oral preservado nesses

\footnotetext{
10 Todos os prédios mencionados por Maia (1996): IFCS (antigo prédio da Escola Politécnica); Faculdade de Direito e Palácio Universitário foram tombados pelo Iphan ou pelo Inepac. Ver: <www.etu.ufrj.br/imoveis_tombados>.

"Pela sua trajetória na instituição, a universidade concedeu o seu nome ao Hospital Universitário.
} 
espaços, sobre a ditadura e sobre outros temas que se relacionam com a história da instituição ou sobre o seu legado social, político, cultural e científico.

Ao refletir sobre as ações de dever de memória na instituição, identificamos que, ao completar quarenta anos do Massacre da Praia Vermelha, em 22 de setembro de 2006, a universidade promoveu uma série de eventos comemorativos tanto no Palácio Universitário, na Praia Vermelha, com show de MPB no Teatro de Arena Carvalho Neto; quanto no Centro de Ciências da Saúde na Cidade Universitária (para onde foi transferida a Faculdade de Medicina), com sessão solene do Conselho Universitário, para lembrar e homenagear os estudantes feridos no episódio da invasão da FNM e deixar registrada uma ação memorialística realizada pela reitoria da UFRJ, com uma placa contendo a imagem dos estudantes feita no dia anterior ao massacre na passeata organizada pela UNE; e a inauguração da exposição intitulada "Rebeldes da Praia Vermelha". Portanto, tanto a invasão quanto a demolição da FNM são eventos dentre outras marcas da memória da ditadura na universidade, e a nossa intenção foi tentar compreender como a universidade lidou com essas memórias e com a preservação desses lugares de memória.

No Brasil, o processo de transição política da ditadura para a democracia construiu uma narrativa de reconciliação com passado, especialmente entre os atores políticos e sociais que apoiaram a ditadura e se mantiveram no poder; esse apaziguamento da história foi reverberado pela Lei de Anistia de 1979. Dessa maneira, as discussões sobre memória, verdade e justiça no país aconteceram de forma tardia em comparação aos outros países latino-americanos, e só foram possíveis com a criação da Comissão Especial dos Mortos e Desparecidos (1995), com a Comissão de Anistia (2001), e mais efetivamente com a criação da Comissão Nacional da Verdade (2011) e da Lei de Acesso à Informação (2012). A partir desses mecanismos sociais, políticos e jurídicos, foi possível o acesso não apenas a documentos oficiais do Estado que estavam sob sigilo, mas também incentivar oitivas públicas, entrevistando diferentes indivíduos ou grupos sociais que tiveram seus direitos humanos violentamente cerceados por atores políticos do Estado. Com isso, pudemos trazer à tona memórias subterrâneas que foram silenciadas (Pollak, 1992) e também abrir a possibilidade de novas pesquisas com acesso a novas fontes. Como destacou Catela (2014, p. 3): "las memorias que durante mucho tiempo fueron subterráneas pasaron a ser oficiales, reconocidas y tomadas como ejes de políticas públicas".

Por fim, precisamos ressaltar que todas essas discussões sobre as memórias em disputa sobre a universidade durante a ditadura ficaram em maior evidência após a instalação da Comissão de Memória e Verdade (CMV) da UFRJ, criada, em julho de 2013, com o intuito de investigar os impactos da ditadura civil-militar e das violações dos direitos humanos no interior da universidade. Atualmente, a comissão está em sua terceira gestão, que se encerrará em 2021. A CMV-UFRJ tem como referência a Comissão Nacional da Verdade (CNV), 
criada em 18 de novembro de 2011 pelo governo federal e que encerrou as suas atividades com a entrega do relatório final em dezembro de 2014.

A instalação das Comissões da Verdade, como analisou Ferreira (2013, p. 46), trouxe para os historiadores que estudam a história do tempo presente além da possibilidade de ampliação de novas questões e objetos de pesquisa, também novos desafios e enfrentamentos, além do alerta para que não nos tornemos juízes da História. O dever de memória está relacionado à ideia de que memórias traumáticas, individuais e coletivas, que passaram por sofrimento e opressão, geram obrigações, por parte do Estado e da sociedade, e também atualizou o debate sobre as relações entre história e memória, provocando discussões acerca do papel do historiador no espaço público (Heymann, 2006, p. 4).

Contribuindo para essa reflexão sobre o dever de memória, ressaltamos que a Comissão da Memória e Verdade da UFRJ, em 2015, além de identificar as principais violações de direitos humanos sofridas por sua comunidade acadêmica, definiu como uma de suas ações de reparação social e institucional a revogação do título de Doutor Honoris Causa concedido ao general presidente Médici pela UFRJ, em 1972, ação aprovada pelo Conselho Universitário e pelo reitor Roberto Leher (2015-2019). Segundo o relatório parcial da CMV-UFRJ (2014), a intenção de anular esse título e outros títulos honoríficos configurava uma "reparação moral aos estudantes e professores da UFRJ torturados, mortos e desaparecidos e como resgate da dignidade acadêmica do Conselho Universitário". Ou seja, é também uma reflexão sobre as responsabilidades da universidade e de seus gestores na colaboração com a ditadura.

É importante lembrarmos que, de acordo com o relatório da Comissão Especial de Mortos e Desaparecidos (CEMD), durante os anos em que Médici governou o país, entre 1969 e 1974, 24 estudantes e dois professores da UFRJ foram mortos ou desapareceram. Nesse sentido, para a comunidade acadêmica, a retirada do título representava uma ação reparadora e um respeito à memória de todos os indivíduos que foram perseguidos, torturados e assassinados com o aval do Estado na figura do presidente, que consentiu tais atos. Ainda sobre a memória da comunidade acadêmica atingida pela repressão do Estado, o relatório parcial da CMV-UFRJ (2014) enfatizou que seria "inadmissível que, ao invés de seus nomes, esteja inscrito na lista dos homenageados desta universidade um dos principais responsáveis pela violência e morte que os vitimou, eles e tantos outros, jovens e não jovens, que não se submeteram ao arbítrio e à brutalidade".

Outro aspecto do dever de memória e reparação no âmbito institucional refere-se à reflexão de que a CMV-UFRJ está sendo secretariada e amparada burocraticamente dentro da estrutura do Fórum de Ciência e Cultura (FCC) da UFRJ. Mesmo com membros de outras unidades da universidade, estabelecendo, com isso, uma diversidade entre seus membros, ainda assim reforçamos que a CMV-UFRJ está se utilizando da estrutura institucional 
e burocrática do FCC, ou seja, do mesmo lugar que durante a ditadura foi um importante ator político para a articulação e disseminação dos principais ideais da repressão e civismo dentro da universidade, sobretudo com a realização das conferências organizadas pelos reitores e coordenadores do FCC para os cursos de Estudos de Problemas Brasileiros.

Cabe destacar que a universidade assumiu publicamente a adoção de uma política de reparação aos atingidos pela ditadura, endossando as ações da CMV-UFRJ, quando cassou o título honorífico do presidente Médici e também quando aprovou o descancelamento da matrícula e o reingresso do ex-aluno Jaime Leis Santiago ao Instituto de História da UFRJ, em 2015. Santiago foi militante da Organização Revolucionária Marxista Política Operária (ORM-Polop). Em 1971, foi expulso da UFRJ, onde cursava História, sendo enquadrado no Decreto-lei n. 477, de 1969, ficando, assim, proibido de retornar para a instituição. Santiago foi obrigado a viver na clandestinidade, mudando inclusive de identidade. Em entrevista ao Jornal da AdUFRJ (n. 855, ago. 2014), ele narrou que tentou o reingresso em 2003, só que foi rejeitado pela Comissão de Orientação e Acompanhamento Acadêmico (Coaa), já que até aquele momento ainda não havia uma política na universidade que possibilitasse a análise de casos de reparação, o que foi modificado com a criação da CMV-UFRJ. Segundo Santiago (Jornal da AdUFRJ, n. 855, ago. 2014),

o meu pedido foi negado porque não fui preso ou processado na época. Mas nós aprendemos na faculdade que a História não é só documental; ela é humana. Eu tinha como provar que fui perseguido, muita gente do curso me conhecia, inclusive professores da instituição, mas eu nem tive a chance de ser ouvido. Com o passar dos anos, não quis mais voltar para a universidade. O novo estímulo veio só depois da criação da Comissão da Verdade da UFRJ, quando fui convidado a dar um depoimento.

Santiago reforçou a importância das oitivas públicas da CMV-UFRJ, que o incentivaram a buscar a reparação de sua memória, pela justiça e pela verdade, a fim de conseguir seu direito de retorno à universidade da qual foi expulso por motivos políticos.

Lembramos que além dos estudantes, ao todo foram 45 professores expulsos da UFRJ durante a ditadura e alguns não retornaram mesmo depois da Anistia de 1979. Sobre isso cabe destacar o importante papel desempenhado pela retomada dos movimentos sociais de esquerda, não somente para o retorno dos exilados ao Brasil, mas, especialmente, para a reintegração dos intelectuais, pesquisadores e professores nas universidades.

Vale salientar, nesse sentido, a atuação da Associação de Docentes da UFRJ (AdUFRJ) que criou campanhas e se empenhou no retorno desse corpo social à universidade. Em 1978, antes mesmo da criação da associação, que data de 26 de abril de 1979, teve início a luta pelo retorno dos professores aposentados compulsoriamente pelo AI-5. Em 26 de junho de 1979, a AdUFRJ realizou uma cerimônia simbólica para reintegrar os professores cassados e, no final 
de 1979, a universidade promoveu a reintegração efetiva dos professores. Como destacou o professor, ex-diretor do Instituto Alberto Luiz Coimbra de Pós-graduação e Pesquisa de Engenharia (Coppe), fundador e primeiro diretor da AdUFRJ, Luiz Pinguelli Rosa (2019, p. 3):

Em um ato solene, demos o título de sócio da AdUFRJ a todos os professores afastados da UFRJ pela ditadura militar, especialmente pelo AI-5. Eram professores que nos davam orgulho. Coube-me ler seus nomes na solenidade em clima de grande emoção: Darcy Ribeiro, Maria Yedda Linhares, Eulália Lobo, José Leite Lopes, Jayme Tiomno, Manoel Maurício Albuquerque, Miriam Limoeiro, Sarah de Castro Barbosa. Plínio Süssekind já tinha falecido, o citamos em memória.

Seja como for, se a universidade buscou mecanismos de reparação aos seus docentes no processo de redemocratização promovendo a reincorporação daqueles que foram perseguidos e expulsos da instituição, mas, no que se refere aos estudantes, essa política de reparação foi muito tardia e só foi possível após a criação da CMV-UFRJ.

\section{Considerações finais}

Foram analisadas algumas memórias em disputa e os impactos da ditadura na UFRJ. O governo militar, ao mesmo tempo em que promoveu uma modernização da universidade, foi conservador e autoritário: com a perseguição e expulsão de seu corpo social, o que provocou o esvaziamento intelectual e científico na instituição; com a interrupção de várias pesquisas e projetos; a censura; a criação de mecanismos de controle, coerção e punição; observamos que, apesar do cerceamento e da eficaz colaboração de parte da comunidade acadêmica com a ditadura ao vigiar e punir os considerados "subversivos" pelo regime autoritário ainda assim os movimentos sociais dentro da instituição conseguiram resistir, seja pelas atividades estudantis, mesmo que clandestinas, ou pela incipiente organização do movimento sindical por parte dos servidores, mas, acima de tudo, por terem lutado pela autonomia universitária.

Este texto buscou promover uma reflexão sobre as memórias em disputa acerca da ditadura civil-militar na UFRJ. Analisando como a universidade construiu as suas memórias oficiais, diante de suas efemérides e comemorações e de seus lugares de memória ligados à ditadura ou não, ora representados pelos agentes da universidade que apoiaram o regime autoritário, ora por aqueles que foram perseguidos por esses agentes da instituição e do governo. E, por fim, com os debates em torno do dever de memória e das políticas recentes de reparação no interior da universidade, conectadas ao trabalho desempenhado pela CMV-UFRJ. 


\section{Referências}

30 ANOS da invasão. Jornal do Cremerj (Rio de Janeiro). 22 set. 1996. (encarte especial). Disponível em: https://www.cremerj.org.br/acervohistorico/download/81;jsessionid=1B330EF2CB8106EA3B217756B8 AF37D9. Acesso em: ago. 2016.

ASSMANN, Aleida. Espaços da recordação: formas e transformações da memória cultural. Campinas: Editora da Unicamp, 2011.

BRITO, Luísa. UFRJ faz evento em homenagem ao Massacre da Praia Vermelha. Gl, O Globo (Rio de Janeiro). 22 set. 2006. Disponível em: http://gl.globo. com/Noticias/Vestibular/0,AA1282192-5604,00ufrj+faz+evento+em+homenagem+ao+massacre+da+praia+vermelha.html. Acesso em: 25 ago. 2020.

CATELA, Ludmila da Silva. Lo que merece ser recordado: conflictos y tensiones en torno a los proyectos públicos sobre los usos del pasado en los sitios de memoria. Clepsidra: Revista Interdisciplinaria de Estudios sobre Memoria (Buenos Aires). n. 2, p. 28-47, oct. 2014.

CATROGA, Fernando. Memória, história e historiografia. Coimbra: Quarteto, 2001.

CMV-UFRJ, Comissão da Memória e Verdade da UFRJ. Relatório parcial. Rio de Janeiro: CMV-UFRJ, 2014.

CORDEIRO, Janaína Martins. A ditadura em tempos de milagre: comemorações, orgulho e consentimento. Rio de Janeiro: Fundação Getúlio Vargas/Faperj, 2015.

CUNHA, Luiz Antônio. A universidade temporã: o ensino superior da Colônia à Era Vargas. $3^{a}$ ed. São Paulo: Editora Unesp, 2007.

EREMILDO Vianna nega que tenha cometido crime em sua carreira. Jornal do Brasil (Rio de Janeiro). $1^{\circ}$ Caderno, 6 abr. 1978, p. 17.

FÁVERO, Maria de Lourdes. Universidade do Brasil: das origens à construção. $2^{\underline{a}}$ ed. Rio de Janeiro: Editora UFRJ, 2010.

FERREIRA, Marieta de Moraes. A História como ofício: a construção de um campo disciplinar. Rio de Janeiro: Editora FGV, 2013.
FREITAS, Adriana da Silva. Repressão aos estudantes da UFRJ no cenário ditatorial. 2014. Dissertação (Mestrado em Serviço Social), Universidade Federal do Rio de Janeiro. Rio de Janeiro, 2014.

GASPARI, Elio. A ditadura envergonhada. São Paulo: Companhia das Letras, 2002.

HEYMANN, Luciana. O 'devoir de mémoire’ na França contemporânea: entre a memória, história, legislação e direitos. Rio de Janeiro: CPDOC/FGV, 2006.

HUYSSEN, Andreas. Seduzidos pela memória: arquitetura, monumentos e mídia. Rio de Janeiro: Aeroplano, 2000.

JORNAL DA ADUFRJ (Rio de Janeiro). n. 855, ago. 2014. Disponível em: https://issuu.com/adufrj/docs/18082014. Acesso em: ago. 2016

MAIA, George Doyle. Biografia de uma faculdade: história e estórias da Faculdade de Medicina da Praia Vermelha. Rio de Janeiro: Atheneu, 1996.

MAIA, Tatyana de Amaral. Os intelectuais no Ministério da Educação e Cultura em tempos autoritários (1966-1982). In: CORDEIRO, Janaína et al. (org.). À sombra das ditaduras: Brasil e América Latina. Rio de Janeiro: Mauad, 2014, p. 51-65.

MOTTA, Rodrigo Patto Sá. As universidades e o regime militar: cultura política brasileira e modernização autoritária. Rio de Janeiro: Zahar, 2014.

MÜLLER, Angélica; FAGUNDES, Pedro Ernesto. O trabalho das comissões da verdade universitárias: rastreando vestígios da repressão nos campi durante a ditadura militar. Ciênciae Cultura (São Paulo). v. 66, n. 4,out.-dez. 2014.

NORA, Pierre. Entre memória e história: a problemática dos lugares. Projeto História (São Paulo). n. 10, p. 7-28, dez. 1993.

OLIVEIRA, Antônio José Barbosa. O Instituto de Puericultura e a Cidade Universitária da Universidade do Brasil. In: AYRES, Leon. Instituto de Puericultura e Pediatria Martagão Gesteira: 60 Anos. Rio de Janeiro: IPPMG/UFRJ, 2013, p. 14-17. 
PEREIRA, Ludmila Gama. O historiador e o agente da História: os embates políticos travados no curso de História da Faculdade Nacional de Filosofia da Universidade do Brasil (1959-1969). Dissertação (Mestrado em História), Universidade Federal Fluminense. Niterói, 2010.

POLLAK, Michael. Memória, esquecimento, silêncio. Estudos Históricos (Rio de Janeiro). v. 2, n. 3, p. 3-15, 1989.

POLLAK, Michael. Memória e identidade social. Estudos Históricos (Rio de Janeiro). v. 5, n. 10, p. 200-212, 1992.

REIS FILHO, Daniel Aarão, Ditadura militar, esquerdas e sociedade. Rio de Janeiro: Jorge Zahar, 2000.

RICOEUR, Paul. Entre mémoire et histoire. Projet (Paris). n. 248, 1996.

ROSA, Luiz Pinguelli. Memórias de luta do primeiro presidente da AdUFRJ. Jornal da AdUFRJ (Rio de Janeiro). n. 1.081, 26 abr. 2019. Disponível em: https:// www.adufrj.org.br/wp-content/uploads/2019/04/ standard40anosweb-1.pdf. Acesso em: 18 ago. 2020.

SANTIAGO JÚNIOR, Francisco. Dos lugares de memória ao patrimônio: emergência e transformação da 'problemática dos lugares'. Projeto História (São Paulo). n. 52, p. 245-279, jan.-abr. 2015. Disponível em: https://revistas.pucsp.br/revph/article/view/21370. Acesso em: 20 nov. 2020.

SILVA, Helenice Rodrigues. Rememoração, comemoração: as utilizações sociais da memória. Revista Brasileira de História (São Paulo). v. 22, n. 44, p. 425 438, 2002.

UFRJ, Universidade Federal do Rio de Janeiro. Discurso do Presidente Emílio Garrastazu Médici ao entregar a cidade universitária aos professores e alunos, no Sesquicentenário da Independência, 7 set. 1972a. Disponível em: http://memoria.sibi.ufrj.br/index.php/acervos/discursos/emilio-garrastazu-medici. Acesso em: 18 ago. 2020.

UFRJ, Universidade Federal do Rio de Janeiro. Saudação do reitor ao presidente Médici, em nome do Conselho Universitário, no Salão Nobre da Reitoria da UFRJ, 7 set. 1972b. Disponível em: http://memoria.sibi.ufrj.br/ index.php/acervos/discursos/emilio-garrastazu-medici. Acesso em: 18 ago. 2020.

UFRJ, Universidade Federal do Rio de Janeiro. Portaria n. 4.966 de 2 de maio de 2013, para a designação da Comissão da Memória e Verdade e do Grupo de Trabalho. Disponível em: http://comissaodaverdade. ifcs.ufrj.br/portaria4966.pdf. Acesso em: 16 maio 2016. 